\title{
The Practical Research on Robot Curriculum of Maker Education in Primary School
}

\author{
Dai Yu-mei ${ }^{1,2}$, Peng Qing-qing ${ }^{1}$, Wang Jian-tong ${ }^{1}$, Dong Huan ${ }^{2}$, Meng Jia ${ }^{1}$ \\ ${ }^{1}$ Normal College, Shenyang University, Shenyang, China \\ ${ }^{2}$ Affiliated Experimental School of Shenyang University, Shenyang, China
}

Email address:

daiyumei66@126.com (Dai Yu-mei), sallypeng@126.com (Peng Qing-qing)

To cite this article:

Dai Yu-mei, Peng Qing-qing, Wang Jian-tong, Dong Huan, Meng Jia. The Practical Research on Robot Curriculum of Maker Education in Primary School. Science Journal of Business and Management. Vol. 5, No. 3, 2017, pp. 105-109. doi: 10.11648/j.sjbm.20170503.13

Received: March 2, 2017; Accepted: April 18, 2017; Published: May 4, 2017

\begin{abstract}
With the rise of Maker movement, Maker Education has been developing quickly around the world. However, there is a lack of systematical and effective curriculum of Maker Education in basic education schools, which can not meet the needs of students' age and personality development, resulting in students' lack of creativity and practical ability. In the light of this situation, this paper integrates robot curriculum which is the extension course of information technology curriculum in primary school with the subject curriculum according to the requirements of the Development of Chinese Students' Core Literacy and the National Curriculum Standards of Information Technology in Basic Education Schools. The instructional design has been made, the course system and teaching mode of the robot curriculum are initially given and the robot curriculum and assessment has been carried out. This research provides reference resources for Maker Education in the basic education schools.
\end{abstract}

Keywords: Robot, Maker Education, Core Literacy, Instructional Design, Information Technology

\section{Introduction}

In recent years, the Maker Movement has attracted more and more attention, in the background of Internet plus education, the influence of Maker Movement has been greatly expanded in space and area and the Maker Education developing quickly. At present, Maker education has been promoted in the reform of basic education, primary and secondary schools across the country are carried out Maker education in full swing [1-3]. Due to the late start of Maker Education in China, there are still many problems in the rapid development of Maker Education, and the main problem is the lack of a high level of maker instructors and systematic and effective maker courses [4-5]. Although there are some educational institutions carrying out Maker Education, as Maker Education is a new thing, educational institutions and enterprises have just started researching on Maker Education curriculum, so the course system is not perfect. The robot course is one of the main courses of Maker Education, Lego robot is widely used in teaching at home and abroad due to its advantages [6-7], but through the study of the LEGO Education WeDo 2.0 curriculum package, LEGO WeDo 2.0 robot only combines with science curriculum of primary school, while ignoring the combination with other subjects, and educational institutions teach only a few students, it is difficult to give robot course in basic education schools. In view of the actual situation, this paper carries out the practical research on robot curriculum of Maker Education in primary school.

\section{Theoretical Basis and Analysis of Learning Situation}

In September 2016, the Development of Chinese Students' the Core Literacy was issued by the Ministry of Education in Beijing Normal University. The development of the core literacy of students is not only an important measure to the implement of fundamental tasks of morality education, but also an urgent need to adapt to the development trend of world education reform and to improve the international competitiveness of China's education [8].

With the development of science and technology, robots are used more and more widely in various fields. Robot technology involves many disciplines and it is a high-tech that world powers focus on in the process of the development. 
It's also a symbol of development level of national science and technology and it plays an important role in the national economy modernization and informatization. In the 2012 edition of the National Curriculum Standards of Information Technology in Primary and Secondary Schools, robot course is an extension module of the information technology curriculum in primary school [9].

At present, the textbook of information technology of Shenyang (Liaoning, China) focus on cultivating students' ability of innovation and practice, and its content covers the required contents of Information Technology Curriculum Guidelines of Primary and Secondary Schools which is issued by the Ministry of Education and the textbook also extent the robot course according to the actual situation Shenyang. The students mastered the basic knowledge of information technology, understand the process of information technology development and its impact on society when they learn other subjects. In the process of learning, they preliminary get the ability of acquisition, transmission, processing and application of information, which lays the foundation for the study of robot [10].

However, in the textbook, there is only one class of the expanding content of robot involved in the sixth grade in primary school. This is not enough for students to learn robot, and according to the National Curriculum Standards of Information Technology in Primary and Secondary Schools, students begin to learn information technology from the third grade, till to the fifth grade, students have had certain information literacy, they have the ability of inquiry and a strong curiosity for new things, and they are able to accept new things quickly. So fifth grade is a good time for robot learning.

Maker Education is not only the mastery and proficiency of "robot" assembly skills, but rather to lead students to master a solid foundation of knowledge and promote the development and growth of advanced thinking. Therefore, based on the theory of constructivism and according to the three aspects of core literacy, this paper focuses on how to improve students' scientific spirit, learning to learn, practice and innovation and strive to build robot curriculum of Maker Education in primary school.

\section{The Practice on Robot Curriculum of Maker Education in Primary School}

This paper takes LEGO Education WeDo 2.0 curriculum package for reference [11] and takes a class (30 students) of fifth grade as the experimental class to carry out robot curriculum of Maker Education in primary school.

\subsection{Curriculum Objectives}

This course is designed to provide students with a basic knowledge of robotics, information technology, sciences, biology, and Chinese by setting up basic experiments on robotics and giving students a preliminary understanding of programming. In terms of learning, helping students form learning consciousness, selecting the appropriate method of study and improving students' ability of self-assessment; in terms of scientific spirit, cultivating students rigorous scientific attitude, improving students' logic thinking ability and training students to have the courage to explore the scientific spirit of criticism; in terms of practical innovation, cultivating students practical innovation ability and innovation consciousness in their daily activities, problem solving and adapting to the challenges.

\subsection{Curriculum Structure and Specific Content}

In this paper, the design of the structure of robot curriculum of Maker Education in primary school as shown in Figure 1.

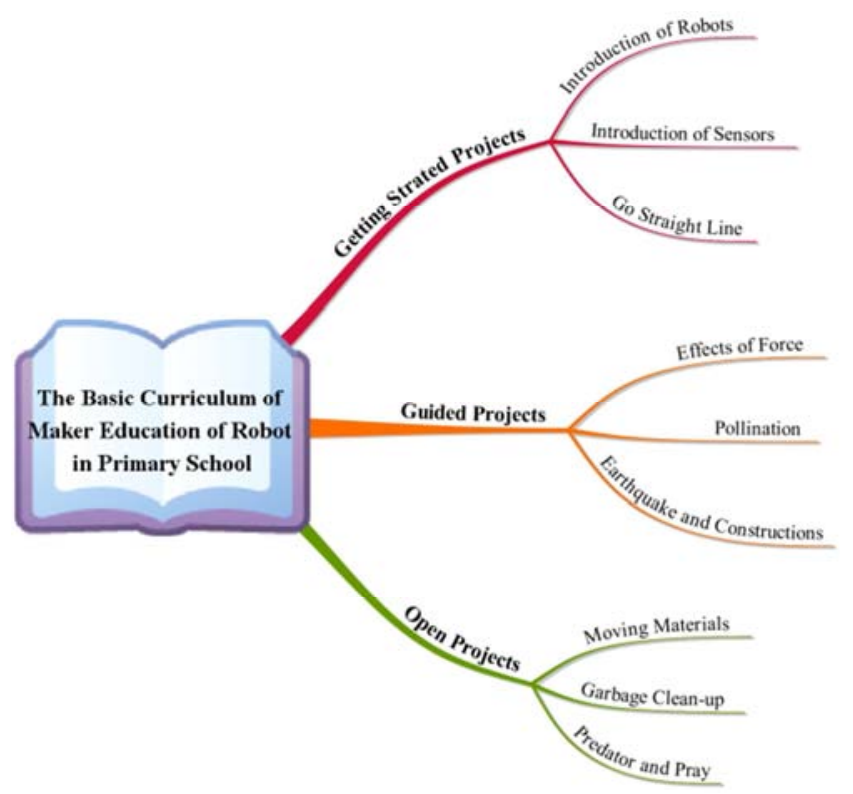

Figure 1. The Structure of robot curriculum of Maker Education in primary school.

There are three types of experiments in LEGO WeDo 2.0 course package: getting started projects, guided projects and open projects. According to the course package, three types of experiments are screened and sorted out. Based on this, the innovation practice is carried out, and the original content of the course package is added or deleted and also integrates with many subjects.

In getting started projects, three groups of experiments are designed and reorganized: introduction of robots, introduction of sensors and go straight line, aiming to help students master how to use and operate WeDo 2.0. Knowledge of getting started project includes: what is a robot; types of robot; science rover; how to use WeDo 2.0; function of WeDo 2.0 programming block; how to use motor; gear; what is the sensor; the use of sensors; the motion sensor and tilt sensor of WeDo 2.0.

In guided projects, three groups of experiments are designed and reorganized: effects of force, pollination and earthquake and constructions, providing clear steps to help students complete the experiment. Knowledge of guided project includes: what is force; common force in life; tension and friction; how to move the object; lever; gear; pulley; composition part of flowers; 
pollination; pollinators; plants and pollinators; gears and motion sensors; the cause of the earthquake; the hazards of earthquakes; intensity and magnitude; supporting rod and piston; features of anti-seismic building.

In open projects, three groups of experiments are designed and reorganized: predator and pray, garbage clean-up and moving materials, aiming to give students a more open environment for exploration and more learning experiences. Knowledge of open project includes: what is the food chain; the role of the food chain; predator and prey; gear; environmental impact on human life; classification of garbage; the important role of handling tools in life; lever; pulley. All of the experiments are the extension of information technology, and has deep integration with the subjects such as science and Chinese language.

\subsection{Teaching Mode}

Combined with local and actual situation, nine groups of experiments are designed and reorganized and according to the WeDo 2.0 course package, each experiment adopts "three stages" teaching mode to complete the whole teaching: Explore Phase, Create Phase and Share Phase.

(1) Explore Phase

This phase mainly connects the students to learning topic, helps students maintain a positive learning attitude and focus on the topic at the beginning of the class, through the activities related to life phenomenon, video and the experiments stimulating students interest in learning, enable students to clear the learning objectives and the main content of the study, develop good learning habits and find their own learning methods. According to the content of the introduction part, puts forward questions related to the experiment, let the students think and explore the questions.

This phase is mainly to cultivate students' ability of discovering questions, have the interest and enthusiasm to solve the problem; choose and formulate reasonable solutions according to the specific situations and conditions and also have the ability to take action in complex environments.

(2) Create Phase

This phase is mainly for students making changes and innovating on basic tasks. It is an important stage for students to reflect, develop and cultivate their innovative ability. Students will try to build robots and programming, their hands-on ability will be exercised and efficiency consciousness will be improved. First of all, students will form a problem awareness, they will analysis problems didactically and make choices and decisions; second, be not afraid of difficulties, unremitting exploration spirit; finally, be bold attempt to actively seek effective solutions of problem. When students encounter problems, teachers should give positive help and guidance.

Through this phase of training, students' scientific spirit and innovation ability will be greatly improved, and gradually formed the engineering thinking.

(3) Share Phase

This phase mainly gives students the opportunity to display their own experimental results, the display could be in the form of personal display and also be displayed cooperation between groups. Students' learning document can be preserved and the assessment can be made after class. This phase can help students the form the awareness of examining their own learning, cultivate the habit of self-assessment, according to different situations and their actual situations, select and adjust the learning strategies and methods.

In this phase, students should also learn the advantages of other students, keep the sense of team spirit, mutual aid and the consciousness of lifelong learning, while maintaining the spirit of criticism and questioning the unreasonable thing.

\section{The Assessment of Teaching Practice of Robot Curriculum of Maker Education in Primary School}

The assessment of education quality has an important guiding role, and it's a very important link in the teaching process. The assessment system of robot course in primary school is not mature [12], but according to Guidance on Promoting the Reform of Comprehensive Assessment of the Quality of Education in Primary and Middle Schools which issued by the Ministry of Education, the combination of quantitative assessment and qualitative assessment should be used in the assessment of teaching process of curriculum in primary and secondary schools and formative assessment and summative assessment should be combined, pay attention to examine the degree of students' progress and the degree of efforts of schools, do not just emphasize the results and pay more attention to the practice of development. The internal assessment (self-assessment) and external assessment (teacher-led assessment, assessment of other study groups') should be combined and focusing on promoting schools to establish the quality of internal control mechanism, do not relying too heavily on external evaluation and ignore the practice of self diagnosis and self improvement.

In the practical process of the robot curriculum of Maker Education, teacher-led assessment and students' self assessment and reflection are mainly adopted.

\subsection{Teacher-Led Assessment}

The teacher-led assessment is mainly based on the observation rubrics grid provided in the WeDo 2.0 course package. The evaluation standard is based on the standards in the WeDo 2.0 course package, and also refer to the three specific aspects of the development of Chinese students' core literacy: learning to learn, scientific spirit, practice and innovation.

Standard of the assessment is divided into four grades for each teaching phase: emerging 1 points, developing 2 points, proficient 3 points and accomplished 4 points.

(1) Emerging

The student is at the beginning stages of development in terms of content knowledge, ability to understand and apply content, and/or demonstration of coherent thoughts about a given topic. Learning attitude is correct, can take the initiative to learn; with scientific spirit, the courage to 
explore, willing to practice innovation.

(2) Developing

The student is able to present basic knowledge only (vocabulary, for example) and cannot yet apply content knowledge or demonstrate comprehension of concepts being presented. The student has strong interest in learning and good study habits; full of curiosity, imagination and scientific spirit, able to think independently, and good at hands-on practice.

(3) Proficient

The student has concrete levels of comprehension of content and concepts and can demonstrate adequately the topics, content, or concepts being taught. The ability to discuss and apply outside the required assignment is lacking. The student has a positive attitude towards learning and a strong interest in learning; have good learning habits and can master their own learning methods; to boldly try to actively seek effective problem-solving methods.

(4) Accomplished

The pupil can take concepts and ideas to the next level, apply concepts to other situations, and synthesise, apply, and extend knowledge to discussions that include extensions of ideas. The student has the ability to choose and adjust learning strategies and methods according to different situations and their own reality and can consciously and effectively acquire, evaluate, identify and use information; advocating true knowledge; with logical thinking and engineering thinking, ideas and programs can be transformed into tangible items or to improve and optimize existing items.

After the teaching practice, the data of the teacher-led assessment are analyzed and drawing the graph according to the results of the analysis in order to observes students' variation trend of explore phase, create phase and share phase, like Figure 2 shows.

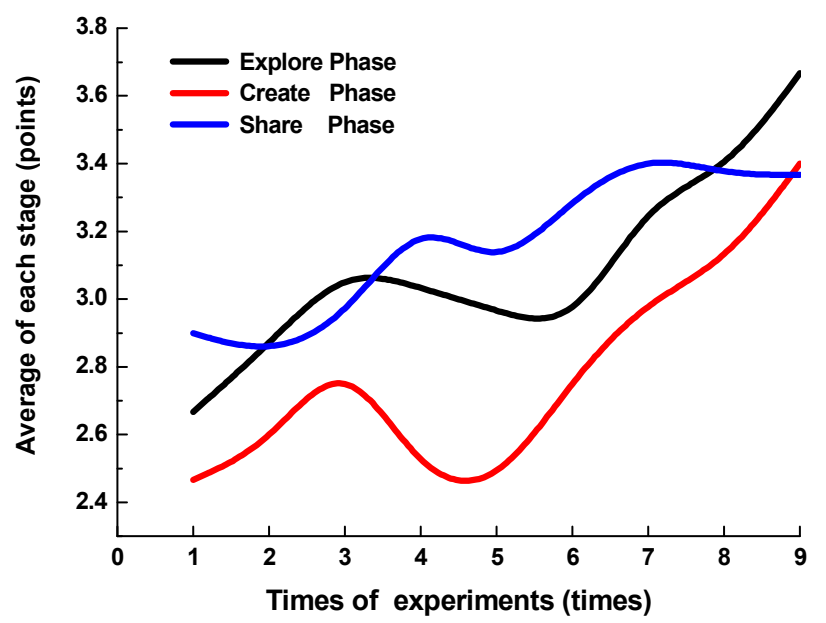

Figure 2. The Graph of Teacher-led Assessment Data of Students in Each Phase.

Figure 2 takes the class (30 students) of fifth grade as the experimental class, collected the points of 30 students in each phase, a total of nine times the experimental data. Each data point in the graph is the average of 30 students' points for each experiment. Figure 2 shows the trend of the development of students' ability in each phase in the whole robot course. Students tend to do well in the explore phase and share phase, and in the create phase students' performance is a bit poor. But in all the three phases, students' ability are showing a rising trend, especially with the deepening of courses, upward trend of the ability in the create phase is more prominent.

\subsection{Students'Self-Assessment and Self-Reflection}

\subsubsection{Students'Self-Assessment}

The content of students' self-assessment corresponds to the three stages of the experiment, each stage has a unified assessment index, assessment criteria for 1 point, 2 points, 3 points, that is, good, better and best.

(1) Students' Self-assessment Index of Explore Phase

I have a strong interest and actively participated in the activities. I documented and used my best reasoning in connection with the question or problem.

(2) Students' Self-assessment Index of Create Phase

I did my best work to solve the problem or question by building and programming my model and making changes when needed.

(3) Students' Self-assessment Index of Share Phase

I documented important ideas and evidence throughout my project and did my very best when presenting to others.

According to the situation of students' self-assessment, the fifth grade students have the ability of self-assessment, but most of the students can not make an objective assessment of themselves, so the analysis of assessment results is by teacher-led assessment mainly.

\subsubsection{Students'Self-Reflection}

There are two questions in the students' self-reflection: 1) One thing I did really well was; 2 ) One thing I want to improve on for next time is. According to students self-reflection data to draw students' self-reflection pie chart, as shown in Figure 3 and Figure 4.

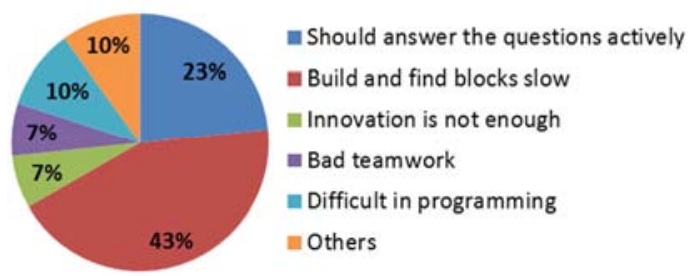

Figure 3. Pie Chart of Students' Self-reflection -The Thing They Want to Improve.

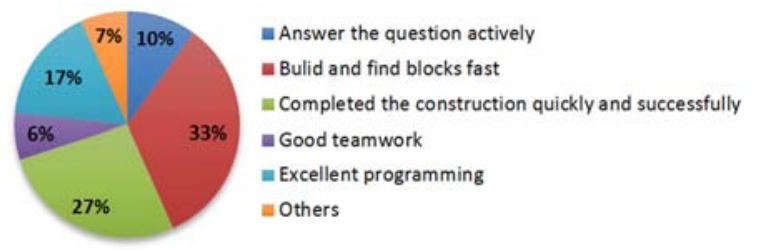

Figure 4. Pie Chart of Students' Self-reflection -The Thing They Did Really Well.

As it can be seen from pie chart in Figure 3 and Figure 4, students are able to recognize their own strengths and weaknesses. 
In Figure 3, 43\% of the students think that building and looking for block is slow, which indirectly reflects the majority of students think that time of class is limited, so that they do not have enough time to do their own innovation, so they think that they need to speed up; $23 \%$ of the students think they do not actively answer the questions in class, from this point it can be seen that this part of students have the initiative to learn and they want to actively participate in classroom activities. This means teachers should pay more attention to each student in class and give opportunity to each student.

According to the statistical information of Figure 4, most of the students think that they have completed the construction quickly and successfully, which reflects the students' strong practical ability.

In a word, through students' self assessment and self-reflection, it can be seen that students have the ability of self-awareness and assessment. Some students have deeper understanding of their own shortcomings, however, the students understanding of themselves is not comprehensive, in the process of data analysis, find that they just find only one to two advantages and disadvantages of themselves, so the teachers-led assessment and students' self assessment should be combined. Teachers should help and guide the students according to their strengths and weaknesses.

\section{Conclusion}

Through the deep integration of robot, science and Chinese, the overall framework of robot curriculum of Maker Education in primary school has been built, the "three stage" teaching mode has been designed. Through the theory and practice research, the universality of the robotics curriculum in the basic education school can be realized and some teaching references of robot curriculum of Maker Education and the new way of carrying out the Maker Education have been provided to the basic education schools. Through the analysis of the teaching practice, it can be seen that students' ability has been improved in explore phase, create phase and share phase of the robot curriculum of Maker Education. As the extension part of information technology in primary school, the robot curriculum of Maker Education plays an important role in cultivating students' learning to learn, scientific spirit and ability of innovative practice.

\section{Acknowledgements}

This research is supported by grants from the "2016 National University Students Innovation and Entrepreneurship Training Program Project Funds", "“'Yuanmengyuan" Primary and Secondary Education Practice Research" (Project Number: 201611035023).

This research is the result of the Youth Project of the National Education Information Technology Research of 2016, "Practical Research on Maker Education in Basic Education Schools by Using University Resources" (Project Number: 166243175).

This research is the result of the Subject of "Double Service" Key Project of Shenyang Education System of 2016, "Practical
Research on Maker Education in Basic Education Schools by Using University Resources (Project Number: 201610)”.

\section{References}

[1] Halverson, E. R. and Sheridan, K. (2014), "The maker movement in education," Harvard Educational Review, vol. 84(4), 2014, pp. 495-504.

[2] Martin, L., "The promise of the Maker Movement for education," Journal of Pre-College Engineering Education Research (J-PEER), vol. 5(1), 2015, pp. 30-39.

[3] Dougherty, D., The maker mindset. M. Honey \& D. E. Kanter (Eds.), Design, make, play: Growing the next generation of STEM innovators, New York, NY: Routledge, 2013, pp. 7-11.

[4] Yang Xianmin and Li Jihong, "The Potential Value of Maker Education and Its Disputes," Modern Distance Education Research, (2), 2015, pp. 23-34.

[5] Zhu Zhiting and Sun Yanyan, "Maker Education: a Practical Field of ICT-Enabling Innovation Education," China Educational Technology, (1), 2015, pp. 14-21.

[6] Karolína Mayerové and Michaela Veselovská, How to Teach with LEGO WeDo at Primary School. M. Merdan, W. Lepuschitz, G. Koppensteiner, B. Richard. Robotics in Education, Switzerland: Springer International Publishing, 2016, pp. 55-62.

[7] David P. Miller and Illah Nourbakhsh, Robotics for Education. Bruno Siciliano, Oussama Khatib, Springer Handbook of Robotics. Switzerland: Springer International Publishing, 2016, pp. 2115-2134.

[8] Anonymous, "The Overall Framework of the Development of Chinese Students' Core Literacy Released Officially," Shanghai Education, (27), 2016, pp. 9.

[9] Li Yi and Xie Zuoru, "How Does Robot Education Enter Primary and Secondary Class," China Information Technology Education, (10), 2015, pp. 4-9.

[10] Liu Li, Information Technology, Shenyang: Shenyang Publishing House, 2016.

[11] LEGO Education WeDo 2.0.

[12] Wang Tongju, "Research on the Evaluation Method of Robot Teaching in Primary and Secondary Schools," Educational Information Technology, (6), 2015, pp. 75-78.

\section{Biography}

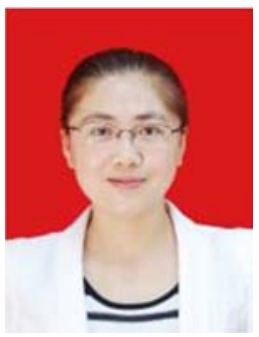

Dai Yumei, Professor, Doctor of Technical Science, master tutor of modern educational technology in Shenyang University, Vice President of Affiliated Experimental School of Shenyang University, Deputy Director of Modern Education Technology Research Institute of Shenyang University, mainly research on the theory and practice of maker education and the theory and practice of information technology and curriculum integration. 